\title{
Intravascular lithotripsy for the treatment of a heavily calcified recurrent in-stent restenosis in a patient with chronic coronary syndrome
}

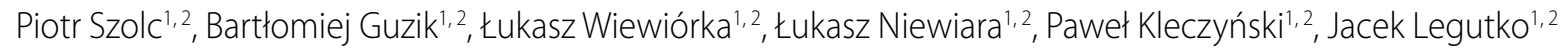 \\ 'Clinical Department of Interventional Cardiology, John Paul II Hospital, Kraków, Poland \\ 2Department of Interventional Cardiology, Faculty of Medicine, Institute of Cardiology, Jagiellonian University Medical College, Kraków, Poland
}

\author{
Correspondence to: \\ Prof. Jacek Legutko, MD, \\ PhD, FESC, \\ Clinical Department of \\ Interventional Cardiology, \\ John Paul II Hospital, \\ Prądnicka 80, \\ 31-202 Kraków, Poland \\ phone: +48 126143501 , \\ e-mail: \\ jacek.legutko@uj.edu.pl \\ Copyright by the Author(s), \\ 2021 \\ Kardiol Pol. 2021; \\ 79 (10): $1159-1160$ \\ DOl: 10.33963/KP.a2021.0079 \\ Received: \\ March 15, 2021 \\ Revision accepted: \\ July 29, 2021 \\ Published online: \\ August 2, 2021
}

We present a case of a 67-year-old male patient admitted to our Department due to recurrence of angina class II according to the Canadian Cardiovascular Society scale. The past medical history included primary percutaneous coronary intervention ( $\mathrm{PCl}$ ) of the left anterior descending artery (LAD) with a bare-metal stent in 2005 and repeated PCI of the LAD with a sirolimus-eluting stent for in-stent restenosis (ISR) in 2007. Coronary angiography, fluoroscopic digital stent enhancement (DSE), and intravascular ultrasound revealed recurrence of ISR in the proximal segment of the LAD caused by stent under-expansion and heavily calcified neoatherosclerosis (Figure 1A, 1C). Physiology lesion assessment confirmed ischemia (resting full-cycle ratio 0.69 and fractional flow reserve 0.70) (Figure 1B). The patient refused minimally invasive direct coronary artery bypass grafting but agreed to high-risk repeated $\mathrm{PCl}$. A transradial approach with a $6 \mathrm{~F}$ extra-back-up guiding catheter was chosen. Several attempts of lesion predilatation with a non-compliant balloon (NCB) and cutting balloon were ineffective. $A$ very-high-pressure non-compliant balloon deployed at 48 atmospheres did not fully open (Figure 1D). Finally, we performed successful intravascular lithotripsy (IVL) using $3.0 \times 12 \mathrm{~mm}$ IVL balloon catheter (Shockwave Medical, Fremont, CA, USA), which fully expanded at 4 atmospheres. After application of 80 pulses of ultrasound energy, full balloon expansion was achieved (Figure 1E).

New-generation sirolimus-eluting stent was implanted $(3.5 \times 48 \mathrm{~mm})$ at $18 \mathrm{~atm}$ with subsequent NCB optimization. Control angiography showed optimal $\mathrm{PCI}$ result with $<10 \%$ residual diameter stenosis and excellent stent expansion confirmed by DSE (Figure 1F). No complications occurred during the hospital stay, and the patient was discharged home 2 days after $\mathrm{PCl}$ with no symptoms of angina.

Adequate preparation of diffuse, heavily calcified in-stent neoatherosclerosis for stent implantation remains a challenge. In our case several attempts of lesion predilatation with NCB and cutting balloon, or even super-high-pressure NCB, were unsuccessful - no balloon fully expanded. Rotational atherectomy is another option, however, it usually requires the use of a large-size burr ( $\geq 2.0 \mathrm{~mm}$ ), which significantly increases procedural risk [1]. Coronary laser atherectomy could be an option; yet, it is not widely available. Therefore, we decided to use a novel method of calcified lesion preparation for stent implantation - IVL [2]. The effectiveness of IVL has been already described in the primary treatment of severely calcified native coronary lesions [2, 3]. There is a single published case report describing off-label IVL application to treat calcified in-stent neoatherosclerosis as an adjunct to rotational atherectomy [4]. Salazar et al. reported successful IVL application as treatment of recurrent, calcified in-stent atherosclerosis in a diagonal branch [5]. We report for the first time a direct application of IVL to treat ISR caused by 13-year-old neoatherosclerosis in the previously double stented lesion in the proximal LAD. This represents a new, extremely promising, and easy-to-use treatment strategy (without a learning curve) for this high-risk lesion subset. However, its short-time safety and long-time effectiveness need to be proven in large-scale clinical trials. 

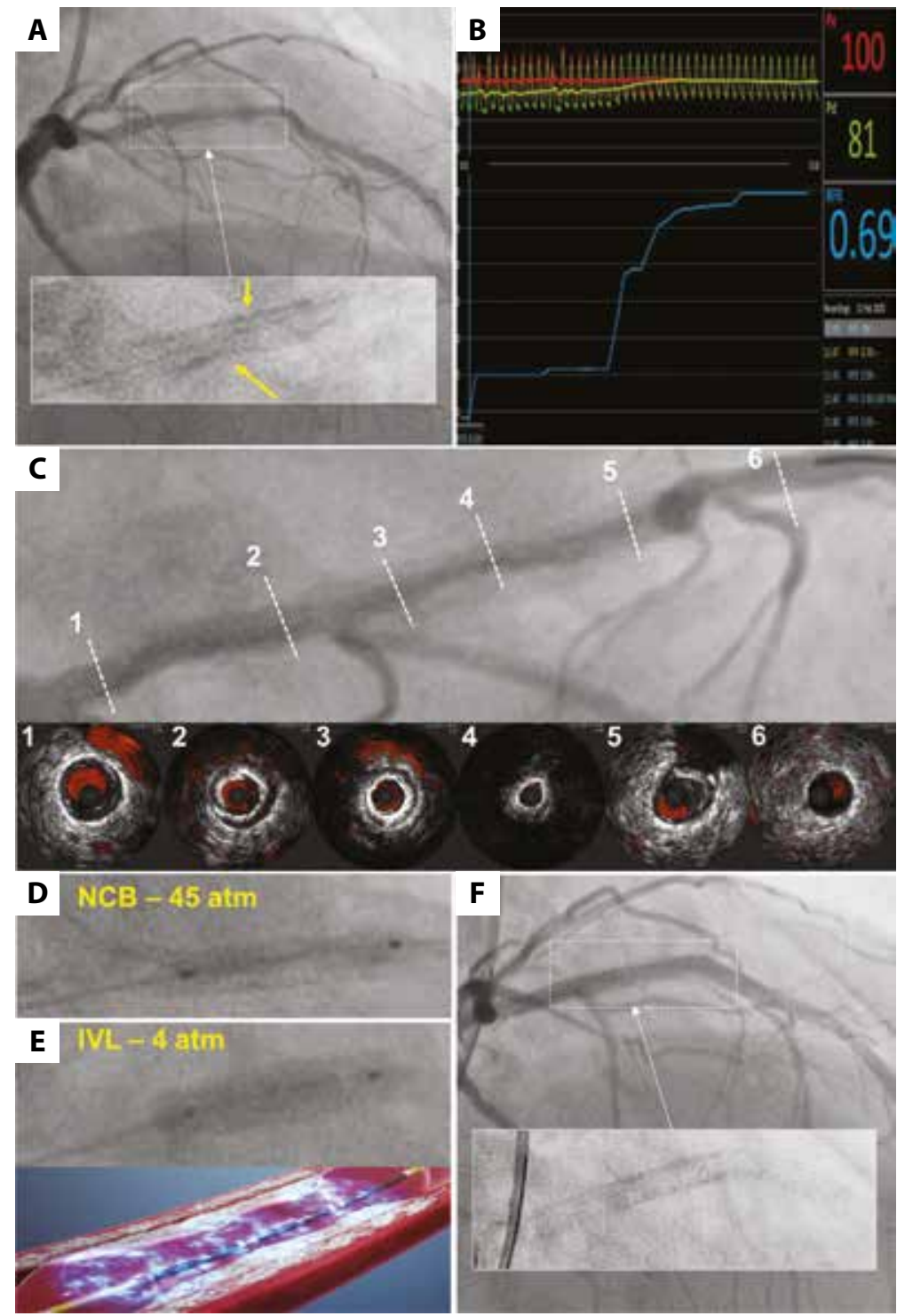

Figure 1. A. Coronary angiography revealed diffuse in-stent restenosis in the proximal segment of the LAD. Severe calcifications within stented segment of LAD and stent underexpansion (arrows) visible on fluoroscopic DSE. B. Physiology lesion assessment confirmed ischemia in LAD. C. IVUS revealed heavily calcified neoatherosclerosis as a cause of ISR (diffuse, multi-layered neointima with severe calcifications [up to $360^{\circ}$ of superficial calcium arc at the site of maximum lumen narrowing]) within double stent strut layer. D. Very-high-pressure non-compliant balloon deployed at 48 atmospheres not fully opened in fluoroscopy. E. Intravascular lithotripsy balloon fully expanded at 4 atmospheres (upper picture). Schematic illustration of intravascular lithotripsy balloon catheter (lower picture). F. Final angiographic result with $<10 \%$ diameter stenosis and optimal stent expansion confirmed by DSE

Abbreviations: DSE, digital stent enhancement; ISR, in-stent restenosis; IVUS, intravascular ultrasound; $L A D$, left anterior descending artery

\section{Article information}

Conflict of interest: None declared.

Open access: This article is available in open access under Creative Common Attribution-Non-Commercial-No Derivatives 4.0 International (CC BY-NC-ND 4.0) license, allowing to download articles and share them with others as long as they credit the authors and the publisher, but without permission to change them in any way or use them commercially. For commercial use, please contact the journal office at kardiologiapolska@ptkardio.pl.

How to cite: Szolc P, Guzik B, Wiewiórka $Ł$, et al. Intravascular lithotripsy for the treatment of a heavily calcified recurrent in-stent restenosis in patient with chronic coronary syndrome. Kardiol Pol. 2021; 79(10): 1159-1160, doi: 10.33963/KP.a2021.0079.

\section{REFERENCES}

1. Dobrzycki S, Reczuch K, Legutko J, et al. Rotational atherectomy in everyday clinical practice. Association of Cardiovascular Interventions of the Polish Society of Cardiology (Asocjacja Interwencji Sercowo-Naczyniowych Polskiego Towarzystwa Kardiologicznego - AISN PTK): Expert opinion. Kardiol Pol. 2018; 76(11): 1576-1584, doi: 10.5603/KP.2018.0225, indexed in Pubmed: 30460675.

2. Hill JM, Kereiakes DJ, Shlofmitz RA, et al. Disrupt CAD III Investigators. Intravascular lithotripsy for treatment of severely calcified coronary artery disease. J Am Coll Cardiol. 2020; 76(22): 2635-2646, doi: 10.1016/j. jacc.2020.09.603, indexed in Pubmed: 33069849.

3. Legutko J, Niewiara Ł, Tomala M, et al. Successful shockwave intravascular lithotripsy for a severely calcified and undilatable left anterior descending coronary artery lesion in a patient with recurrent myocardial infarction. Kardiol Pol. 2019; 77(7-8): 723-725, doi: 10.33963/KP.14859, indexed in Pubmed: 31171761.

4. Chen G, Zrenner B, Pyxaras SA. Combined rotational atherectomy and intravascular lithotripsy for the treatment of severely calcified in-stent neoatherosclerosis: a mini-review. Cardiovasc Revasc Med. 2019; 20(9): 819-821, doi: 10.1016/j.carrev.2018.10.007, indexed in Pubmed: 30409500.

5. Salazar C, Escaned J, Tirado G, et al. Intravascular lithotripsy for recurrent restenosis caused by severe calcific neoatherosclerosis. Eurolntervention. 2020; 16(4): e351-e352, doi: 10.4244/EIJ-D-19-00268, indexed in Pubmed: 31334702 